\title{
Impact of Selected Soil and Water Conservation Measures on Sustainability of Soil Moisture Content at Bambasi District, Benishangul Gumuz Region, Ethiopia
}

\author{
Tekilil Wolde ${ }^{1, *}$, Alemu Bade ${ }^{2}$ \\ ${ }^{1}$ Department of Natural Resource Management, College of Agriculture and Natural Resource, Wolkite University, Wolkite, Ethiopia \\ ${ }^{2}$ Department of Horticulture, College of Agriculture and Natural Resource, Wolkite University, Wolkite, Ethiopia
}

Email address:

woldetekilil@gmail.com (T. Wolde), alexbehite21@gmail.com (A. Bade)

${ }^{*}$ Corresponding author

\section{To cite this article:}

Tekilil Wolde, Alemu Bade. Impact of Selected Soil and Water Conservation Measures on Sustainability of Soil Moisture Content at Bambasi District, Benishangul Gumuz Region, Ethiopia. Journal of Energy, Environmental \& Chemical Engineering.

Vol. 5, No. 3, 2020, pp. 42-47. doi: 10.11648/j.jeece.20200503.12

Received: February 25, 2020; Accepted: March 4, 2020; Published: October 13, 2020

\begin{abstract}
Conservation of soil and water resources is important for sustainability of agriculture and environment. Soil and water resources are under immense pressure due to ever increasing population thereby ensuring growing demand for food, fiber and shelter. Soil and water resources are being deteriorated due to different anthropogenic and natural factors. Soil erosion is one of the several major deteriorative processes which results in deterioration of the soil. Agriculture in Ethiopia is subjected by rain fed farming with low productivity especially dry land Part of the country, like bambasi distrct of Benishangul gumuz region. As a result, crops have severe moisture stress through their growth stages. Therefore, a field experiment was conducted at bambasi distrct farmers own land by newly established selected conservation measures in the year of 2016 to analyze the impact of selected soil and water conservation measures (soil bund, grass mulch and contour cultivation), enhancing soil moisture and thereby land productivity. The experiment was arranged in a random complete block design with three replications. The analysis of variance for the results of the study indicated that significant differences were observed in soil moisture content at different soil depths at an interval of 15 days. Statistically not significant measurement were recorded between soil bund and contour cultivation in some measuring interval and depths, but reasonable difference was obtained in grass mulch treatment throughout the season in all measuring depth. Therefore, grass mulch should be recommended to reduce the risk of moisture stress and to ensure sustainability of soil moisture in the study area.
\end{abstract}

Keywords: Soil Moisture, Soil and Water Conservation Measure, Soil /water Resource

\section{Introduction}

Most farmers are poor and operate at subsistence level and investment for intensification of agriculture is not well developed in the country. This has created a vicious circle of low productivity land degradation reduces the production potential of the land and this, in return makes it difficult for farmers to produce enough and Land degradation in the form of soil erosion, sedimentation, depletion of nutrients deforestation and over grazing is one of the basic problem facing farmers in the Ethiopia high land and this limits their ability to increase agricultural production and reduce poverty and food insecurity. The integrated process of land degradation and increased poverty has been referred as the downhill spiral of un-sustainability" leading to the poverty trap [6].

Soil erosion is one of the largest global problems resulting both on -site and off-site effects. Soil erosion has accelerated in most parts of the world, especially in developing countries, due to different socio-economic and demographic factors and limited resources [5]. The backbone of the agrarian economy in most developing countries is rain fed agriculture. The 
economic development of developing countries depends on the performance of the agricultural sector and the contribution of the sector depends on who the natural resources are managed. The quality and quantity natural resources are decries resulting in more severe droughts and floods. Effective integrity SWC management can reduce these effects. Ethiopia is one of the poorest countries in the world [11].

The immediate consequence of land degradation is reduced crop yield followed by economic decline and social stress. Soil erosion is the main form of land degradation, caused by the interacting effects of factors, such as biophysical characteristics \& socioeconomic aspects. Degradation resulting from soil erosion \& nutrient depletion is one of the most challenging environmental problems in Ethiopia. The Ethiopian high lands have been experiencing declining of soil fertility \&sever soil erosion due to intensive farming on steep \& fragile land [3]. Recognition land degradation as major environment and socio-economic problem, the government of Ethiopia has made several interventions. As a result, large areas have been converted to terraces, covered by soil bunds, closed by area closures and planted with millions of tree seedlings. Nevertheless, the achievements have fallen far below expectations. The country still loses a tremendous amount of fertile topsoil, and the threat of land degradation is broadening alarmingly [8].

Its economy is based on mainly agriculture providing employment for over $80 \%$ labor force which accounts for a little over $50 \%$ of GDP. In fact, agriculture in Ethiopia is not only an economic activity but also way of life for which agricultural land is an indispensable resource upon which the welfare of the society is built. The livelihood of the vast majority of the population depends directly or in directly on this sector. Such dependence obviously lends to increased vulnerability of the economy problems related to land degradation [10].

\subsection{Statement of the Problem}

In developing countries like Ethiopia there is poor approach of soil and water conservation practices unlike developed countries [12]. The developing countries do not give more consideration to the application of soil and water conservation practices that can limit their living standard related with economic development. Soil degradation accredited to erosion is one of the serious environmental problems in Bambasi district. Despite the fact that various soil conservation methods such as cover crop, crop rotation, soil bund, fanya juu bund, check dam, terracing were introduces by the government through agricultural office of the district and practices in the field, but the extents of adoption of such measures and the sustainability soil moisture are not clear, not indentify and leads to a serious problem leading to low yields [14]. Therefore, this study was aims to ensure the selected soil and water conservation measure and sustainability of moisture content.

\subsection{Objective of the Study}

\subsubsection{General Objective}

To assess impact the selected soil and water conservation measures on sustainability of soil moisture content at bambasi district, benishangul gumuz region, Ethiopia

\subsubsection{Specific Objective}

To identify the different soil and water conservation measures in study area.

To assess the impact of selected measures on sustainability of soil moisture content in study area.

\subsection{Research Questions}

What are effective soil and water conservation measures?

How do you relate the age, maintenance, of soil and water conservation measures with soil moisture content?

\subsection{Scope of the Study}

The scope of this study was to assess the impact of soil and water conservation measures on soil moisture content in the study area of Bambasi district. It was mainly confined biophysical soil and water conservation measures and the effectiveness on agricultural productivity and determining factors affecting the conduction of biophysical soil and water conservation measures in the study area. The further investigation of all facts /related issues were limited due to financial and time constraints, therefore the study was confined to only Bambasi district.

\subsection{Significance of the Study Area}

This research is likely to have imperative contributions for the study areas by creating strong awareness on the level of farmers' knowledge, attitude and practice about soil erosion and could be used to take solution measure on soil erosion. Also gives useful information for users working to solve soil erosion and other environmental related problems. At the end farming community have better understanding on soil and water conservation measures effect on soil moisture content.

\section{Material and Method}

\subsection{Description of the Study Area}

The bambasi district is $611 \mathrm{~km}$ away from Addis Ababa through the Nekemte road in the western direction. The district has wider land forms, plains, plateaus valleys and mountains. The district has diverse climate with widely varying altitude range of 1000 to $1500 \mathrm{~m}$ a. s. 1 (BDADO, 2015). Most of the agro-ecological zone of bambasi district is kola, but it consists least of ecological zone of "Weyna Dega". The average temperature of the District is $27.4^{\circ} \mathrm{C}$. The average annual rainfall of the District is $900-1400 \mathrm{~mm}$. The rain fall pattern of the area is characterized as uniformly distribution through the growing seasons which starts in May 
and extends to about end of September, and has erratic pattern to end of October. The dry season starts in November and extends to end of April. The soil is clay in texture. Maize, mango, and sorghum are the dominant crops grown in the area (BDADO, 2015). The soil is clay in texture. Mango is the dominant fruit crops grown in the area. Maize and sorghum are the dominant field crops grown in the area (BDADO, 2015).

\subsection{Sampling Techniques and Sampling Size}

The study was used both purposive, random and stratify sampling techniques, first bambasi district was selected by purposive sampling, due to the area is potential for different soil and water conservation measures applications based on field observation and as district agricultural office information. Random sampling technique was employed to select representative soil and water conservation measures among the different newly established measures (soil bund, contour cultivation, and grass mulch) from farmers' own land The stratify sampling techniques was used for selection of representative stakeholder /farmers for qualitative data generation which was based on wealth status (poor $=20$, medium $=20$ ), age (young $=20$, elder $=20$ ), educational level (literate $=20$, illiterate $=20)$, sex $($ male $=20$, female $=20)$. After selection, out of 160 households, $20 \%$ (32 households) were randomly interviewed by using structured questionnaires for the purpose of searching out of sight data for better interpretation. Root zone depth of most crops around study area were expected as $40-60 \mathrm{~cm}$, but most water and nutrient uptake occurs from the top $30 \mathrm{~cm}$ of soil [1]. For this reason, disturbed soil samples were collected up to $(0-40 \mathrm{~cm})$ depth at an interval of $20 \mathrm{~cm}$ with the help of hand auger from each selected conservation measures with an interval of 30 days for moisture determination for up to five months (having a total of six sampling period) which was average cropping season of most crops in study area.

\subsection{Soil Moisture content (SMC) Determination}

The wet soil samples were weighed and placed in an oven at $105^{\circ} \mathrm{C}$ till constant weight attainment and then the weight of dry samples were measured. The following formula [4] was used to calculate the soil moisture content for every sampling period using gravimetric method.

$$
S M C=\frac{W w-W d}{W d} * 100
$$

where:

$\mathrm{SMC}=$ Soil moisture content on mass basis (\%)
$\mathrm{Ww}=$ Weight of the wet soil $(\mathrm{g}) \mathrm{Wd}=$ Weight of the dry soil (g)

The volumetric soil moisture content, $\theta$ (\%) was determined by considering the density of the soil water as 1 $\mathrm{g} / \mathrm{cm}^{3}(\rho \mathrm{w})$.

$$
\theta=W^{*} \rho \mathrm{b}
$$

where:

$\mathrm{W}=$ soil moisture content on mass base (\%) $\rho_{\mathrm{b}}=$ bulk density $\left(\mathrm{g} / \mathrm{cm}^{3}\right)$ of the soil

\subsection{Method of Data Analysis}

In order to address the specified objective and to answer the proposed research questions, the collected data were analyzed, and summarized using SAS software, descriptive statistics was used to analyze qualitative data like age, maintenance, durability and functioning of conservation measures.

\section{Results and Discussions}

\subsection{Descriptive Analysis}

The assessment data of all household and $20 \%$ of household descriptive analysis reported and interpreted as the selected soil and water conservation measure have significant contribution on sustainability of moisture except the poor and illiterate farmers. However, the percentage of respondents is varying among all analyzed variables. Household characteristics (young, elder, poor, medium, male, and female, literate, illiterate) were interpreted with respect to effectiveness of selected soil and water conservation measures on sustainability of soil moisture.

\subsubsection{Age of the Soil and Water Conservation Measures}

The study found that age distribution, economic status, education of farmers have significantly influence the idea of moisture content, conservation measures and age of measures Therefore, elder farmers on all selected measures particularly on grass mulch, significantly more percentage have special understanding on age of measures and the critical effect on moisture content due to long year experience than younger [15]. In addition, economic status (medium) and education status (literate) of the household have a critically difference or positive perception on age of effect of measures on moisture content sustainability compared to others (Table 1).

\begin{tabular}{|c|c|c|c|c|c|c|c|c|}
\hline \multirow{2}{*}{ Measures } & \multicolumn{8}{|c|}{ Farmers' perception (\%) } \\
\hline & Young & Elder $^{\text {a }}$ & Poor & Medium $^{\text {b }}$ & Female & Male & Literate $^{c}$ & Illiterate \\
\hline Soil bund & 70.2 & 82.5 & 57.1 & 69.9 & 71.7 & 79.3 & 78.6 & 61.2 \\
\hline Grass mulch & 79.5 & 93.2 & 61.7 & 74.7 & 88.2 & 89.4 & 91.4 & 67.5 \\
\hline Contour cultivation & 71.6 & 81.5 & 59.2 & 71.3 & 77.5 & 77.2 & 82.3 & 60.3 \\
\hline
\end{tabular}

Table 1. Farmers' perception on age effect of measures on soil moisture content (\%).

Note: a word indicated by powered letters are significant factors compared to others. 


\subsubsection{Maintenance of the Soil and Water Conservation Measures}

The survey analysis also showed that, maintenance effect of grass mulch on soil moisture content was positively influenced by age distribution (elder), economic status (medium), education status (literate) of farmers as compared to others, this was due to living standard and education level has critical role in maintaining and repairing the damaged soil and water conservation structure [12]. However, the age distribution (younger), economic status (poor), education status (illiterate) of farmers have similar perception on maintenance effect of soil bund, contour cultivation on moisture content of soil (Table 2).

Table 2. Farmers' perception on maintenance effect of measures on soil moisture content (\%).

\begin{tabular}{|c|c|c|c|c|c|c|c|c|}
\hline \multirow{2}{*}{ Measures } & \multicolumn{8}{|c|}{ Farmers' perception (\%) } \\
\hline & Young & Elder $^{a}$ & Poor & Medium $^{\text {b }}$ & Female & Male & Literate $^{\mathrm{d}}$ & Illiterate \\
\hline Soil bund & 71 & 81.2 & 55 & 70.2 & 73.4 & 74.2 & 79.5 & $68.9^{f}$ \\
\hline Grass mulch & $88.2^{\mathrm{c}}$ & $92.3^{c}$ & $68^{c}$ & $87.2^{\mathrm{c}}$ & $89.3^{c}$ & $88.3^{\mathrm{c}}$ & $91.7^{\mathrm{c}}$ & $86.8^{\mathrm{c}}$ \\
\hline Contour cultivation & 75 & 80.4 & 52.3 & 72.3 & 75.9 & 77.1 & 80.6 & $67.2^{\mathrm{f}}$ \\
\hline
\end{tabular}

Note: a word indicated by powered letters are significant factors compared to others.

\subsection{Soil Moisture Content (SMC) Determination}

\subsubsection{Soil Moisture Content at the Begging /First Sampling Period}

The analysis of variance illustrate that at this sampling time the table 3 , the moisture retaining structures (soil bund, contour cultivation) have no any significant different effect $(\mathrm{P}>0.05)$ at all soil depths. This may be due to high initial uptake and lack of enough time to decompose any surface material in the soil. Grass mulch influenced soil moisture content significantly $(\mathrm{P} \leq 0.05)$ at all soil sampling depth as compared to soil bund, contour cultivation (Table 3 ). This could be due to the ability of grass to hold more moisture and to reduce evaporation losing [13]. The soil moisture content observed at the depths of $0-20$ and $20-40 \mathrm{~cm}$ also has no significant difference in moisture content in all structures.

Table 3. Moisture Content References at First Sampling Period.

\begin{tabular}{lllll}
\hline \multirow{2}{*}{ Measures } & \multicolumn{4}{l}{ Sampling depth (cm) } \\
\cline { 2 - 5 } & $\mathbf{0 - 2 0}$ & $\mathbf{2 0 - 4 0}$ & & \\
\cline { 2 - 5 } & Mean \pm SE & CV\% & Mean \pm SE & CV\% \\
\hline Soil bund $(\mathrm{Sb})$ & $26.07^{\mathrm{b}} \pm 1.07$ & 11.41 & $26.26^{\mathrm{b}} \pm 0.99$ & 11.16 \\
Grass mulch $(\mathrm{Gm})$ & $28.51^{\mathrm{a}} \pm 1.03$ & 12.61 & $28.96^{\mathrm{a}} \pm 0.99$ & 10.35 \\
Contour cultivation $(\mathrm{Cc})$ & $25.51^{\mathrm{b}} \pm 1.03$ & 10.20 & $26.11^{\mathrm{b}} \pm 0.98$ & 9.60 \\
\hline
\end{tabular}

Note: Treatment means within a column followed by the same letter are not significantly different at $\mathrm{p} \leq 0.05$.

\subsubsection{Soil Moisture Content After 30 Days /Second Sampling Period}

The analysis (Table 4) also shows that the selected measures had brought about a significant difference $(\mathrm{P} \leq$ $0.05)$ at all depths. The highest soil moisture content was observed at 20-40 $\mathrm{cm}$ sample depth compared to all selected measures. But there was no significant moisture difference at 0-20 and 20-40 cm sample depth in soil bund and contour cultivation. The moisture content increments due to the grass mulch were found as $28.51 \%$ and $29.96 \%$ at a depth of 0-20 $\mathrm{cm}$ and $20-40 \mathrm{~cm}$ respectively. The second sampling period had better moisture increment than the first sampling period at all soil depths. The highest $(29.96 \%)$ moisture was observed at $20-40 \mathrm{~cm}$ depth and $28.96 \%$ soil moisture also recorded at $20-40 \mathrm{~cm}$ on the first and second sampling period respectively. This could be due to well incorporation of surface residue (grass) with the soil and water conservation measures these may reduce evaporation losses [7].

Table 4. Moisture Content References after 30 days.

\begin{tabular}{lllll}
\hline \multirow{2}{*}{ Measures } & \multicolumn{4}{l}{ Sampling depth (cm) } \\
\cline { 2 - 5 } & $\mathbf{0 - 2 0}$ & $\mathbf{2 0 - 4 0}$ & & \\
\cline { 2 - 5 } & Mean \pm SE & CV\% & Mean \pm SE & CV\% \\
\hline Soil bund (Sb) & $27.07^{\mathrm{b}} \pm 1.17$ & 11.41 & $25.66^{\mathrm{c}} \pm 1.09$ & 12.16 \\
Grass mulch $(\mathrm{Gm})$ & $28.51^{\mathrm{a}} \pm 1.23$ & 10.41 & $29.96^{\mathrm{d}} \pm 1.19$ & 11.34 \\
Contour cultivation $(\mathrm{Cc})$ & $27.31^{\mathrm{b}} \pm 9.13$ & 9.20 & $25.84^{\mathrm{c}} \pm 0.98$ & 10.60 \\
\hline
\end{tabular}

Note: Treatment means within a column followed by the same letter are not significantly different at $\mathrm{p} \leq 0.05$.

\subsubsection{Soil Moisture Content at 60 Days /Third Sampling Period}

The breakdown of variance also demonstrates that the application of grass mulch had brought about significant difference $(\mathrm{P} \leq 0.05)$ soil moisture in compared to others (Table 5). The highest value of soil moisture content was observed at 20-40 cm sample depth in all selected conservation measures but the lowest soil moisture was recorded at sample depth of $0-20 \mathrm{~cm}$ in measure of soil bund. The highest moisture content due to the application of grass mulch was found as $30.96 \%$ at $20-40 \mathrm{~cm}$ depth. Generally, gravimetric soil moisture at the third sampling period had a significant increment than the second as well as the first sampling period particularly, in grass mulch measures.

Table 5. Moisture Content References after 60 days.

\begin{tabular}{lllll}
\hline \multirow{2}{*}{ Measures } & \multicolumn{4}{l}{ Sampling depth (cm) } \\
\cline { 2 - 5 } & $\mathbf{0 - 2 0}$ & $\mathbf{2 0 - 4 0}$ & & \\
\cline { 2 - 5 } & Mean \pm SE & CV\% & Mean \pm SE & CV\% \\
\hline Soil bund (Sb) & $27.37^{\mathrm{b}} \pm 1.17$ & 11.41 & $28.06^{\mathrm{b}} \pm 0.99$ & 10.16 \\
Grass mulch $(\mathrm{Gm})$ & $29.51^{\mathrm{a}} \pm 1.13$ & 12.51 & $30.96^{\mathrm{a}} \pm 0.99$ & 10.55 \\
Contour cultivation $(\mathrm{Cc})$ & $27.51^{\mathrm{b}} \pm 1.23$ & 11.21 & $28.04^{\mathrm{b}} \pm 0.98$ & 10.60 \\
\hline
\end{tabular}

Note: Treatment means within a column followed by the same letter are not significantly different at $\mathrm{p} \leq 0.05$.

\subsubsection{Soil Moisture Content at 90 Days /Forth Sampling Period}

A perusal of the data on the soil moisture content at the 
days after ninety days of applications (Table 6) revealed that there was a significant difference $(\mathrm{P} \leq 0.05)$ due to the application of grass mulch as compared to others. The highest and lowest values of soil moisture contents were observed at 20-40 and 0-20 cm sample depths respectively. The highest moisture content due to the application of grass mulch was found as $31.96 \%$ and $30.84 \%$ was followed in contour cultivation at a depth of $20-40 \mathrm{~cm}$ in both cases. Soil moisture at this sampling period had a significant increment than the previous sampling time. The highest moisture content (31.96\%), (30.96\%), (29.96\%) and (28.96\%) at 20-40 $\mathrm{cm}$ soil depth were recorded on the fourth, third, second and first sampling period due to grass mulch application respectively.

Table 6. Moisture Content References after 90 days.

\begin{tabular}{lllll}
\hline \multirow{2}{*}{ Measures } & \multicolumn{4}{l}{ Sampling depth (cm) } \\
\cline { 2 - 5 } & $\mathbf{0 - 2 0}$ & $\mathbf{2 0 - 4 0}$ & & \\
\cline { 2 - 5 } & Mean \pm SE & CV\% & Mean \pm SE & CV\% \\
\hline Soil bund (Sb) & $28.07^{\mathrm{b}} \pm 1.17$ & 11.41 & $28.66^{\mathrm{b}} \pm 1.89$ & 12.16 \\
Grass mulch (Gm) & $29.51^{\mathrm{b}} \pm 1.13$ & 12.51 & $31.96^{\mathrm{a}} \pm 0.79$ & 11.35 \\
Contour cultivation & $30.51^{\mathrm{b}} \pm 9.03$ & 11.20 & $30.84^{\mathrm{c}} \pm 1.98$ & 10.60 \\
(Cc) & &
\end{tabular}

Note: Treatment means within a column followed by the same letter are not significantly different at $\mathrm{p} \leq 0.05$.

\subsubsection{Soil Moisture Content at 120 Days / Fifth Sampling Period}

The Table 7 indicates that the application of contour cultivation had a significant change $(P \leq 0.05)$ in soil moisture compared to others. The highest value of soil moisture content was observed at $20-40 \mathrm{~cm}$ sample depth where as the lowest soil moisture was recorded at sample depth of $0-20 \mathrm{~cm}$. The highest moisture content due to the application of contour cultivation was found as $32.84 \%$ at 20 $40 \mathrm{~cm}$ depth. Soil moisture at this sampling period had better increment in contour cultivation than the rest this may be due to increase in stability of soil aggregates. But did not have a significant $(\mathrm{P}>0.05)$ difference in soil bund and grass mulch.

Table 7. Moisture Content References after 120 days

\begin{tabular}{lllll}
\hline \multirow{3}{*}{ Measures } & \multicolumn{4}{l}{ Sampling depth (cm) } \\
\cline { 2 - 5 } & $\mathbf{0 - 2 0}$ & $\mathbf{2 0 - 4 0}$ & & \\
\cline { 2 - 5 } & Mean \pm SE & CV\% & Mean \pm SE & CV\% \\
\hline Soil bund (Sb) & $29.07^{\mathrm{b}} \pm 1.17$ & 11.41 & $29.66^{\mathrm{b}} \pm 1.19$ & 11.12 \\
Grass mulch $(\mathrm{Gm})$ & $29.51^{\mathrm{b}} \pm 0.03$ & 11.31 & $29.96^{\mathrm{b}} \pm 0.98$ & 11.31 \\
Contour cultivation $(\mathrm{Cc})$ & $31.51^{\mathrm{c}} \pm 1.13$ & 10.22 & $32.84^{\mathrm{c}} \pm 0.78$ & 10.63 \\
\hline
\end{tabular}

Note: Treatment means within a column followed by the same letter are not significantly different at $\mathrm{p} \leq 0.05$.

\subsubsection{Soil Moisture Content at 150 Days / Sixth Sampling Period}

Table 8 shows that the application of contour cultivation had brought about significant difference $(\mathrm{P} \leq 0.05)$ in soil moisture as compared to others particularly to soil bund. The highest value of soil moisture content was observed at 20-40 $\mathrm{cm}$ sample depth but the lowest soil moisture was recorded at sample depth of $0-20 \mathrm{~cm}$ in soil bund measures. Application of contour cultivation had better increment in soil moisture than application of grass mulch and soil bund at all sample depths, but contour cultivation had no significant moisture difference between at $0-20 \mathrm{~cm}$ and $20-40 \mathrm{~cm}$ depth. The highest moisture content due to the application of contour cultivation, grass mulch and soil bund measures were found as $33.84 \%, 31.96 \%$ and $30.06 \%$ at a depth of $20-40 \mathrm{~cm}$ respectively.

Table 8. Moisture Content References after 150 days

\begin{tabular}{lllll}
\hline \multirow{3}{*}{ Measures } & \multicolumn{4}{l}{ Sampling depth (cm) } \\
\cline { 2 - 5 } & $\mathbf{0 - 2 0}$ & $\mathbf{2 0 - 4 0}$ & & \\
\cline { 2 - 5 } & Mean \pm SE & CV\% & Mean \pm SE & CV\% \\
\hline Soil bund (Sb) & $29.07^{\mathrm{b}} \pm 1.17$ & 11.31 & $30.06^{\mathrm{b}} \pm 0.89$ & 10.16 \\
Grass mulch (Gm) & $31.51^{\mathrm{a}} \pm 1.03$ & 11.22 & $31.96^{\mathrm{a}} \pm 0.79$ & 11.44 \\
Contour cultivation $(\mathrm{Cc})$ & $32.91^{\mathrm{c}} \pm 1.02$ & 10.21 & $33.84^{\mathrm{c}} 0.68$ & 10.60 \\
\hline
\end{tabular}

Note: Treatment means within a column followed by the same letter are not significantly different at $\mathrm{p} \leq 0.0$.

\subsection{Average Soil Moisture Content of Sampling Period}

Table 9 indicates that there was a significant $(\mathrm{P}<0.05)$ soil moisture difference in soil bund with grass mulch and contour cultivation. However there was no any significant $(\mathrm{P}>$ 0.05) difference observed grass mulch and contour cultivation, different moisture conservation tillage methods that increase the amount of water stored in the soil profile by trapping or holding the applied water [2].

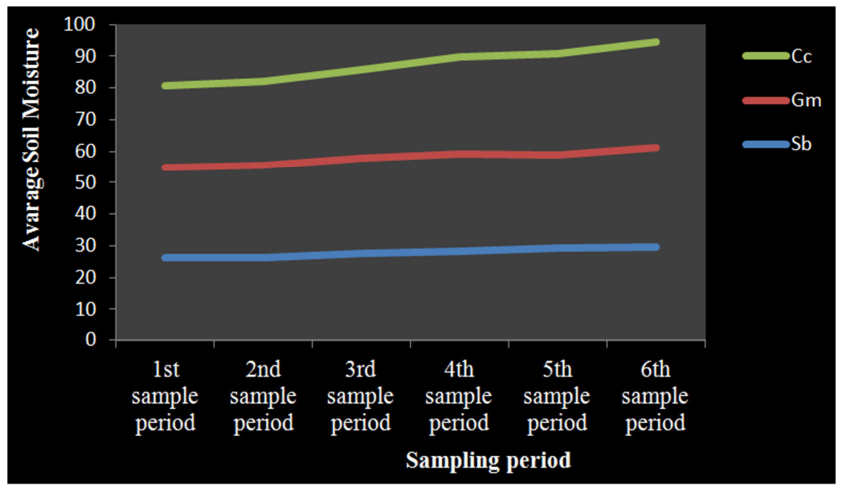

Figure 1. Average moisture content (Mc\%) at 0-40 cm soil depth on different sampling period.

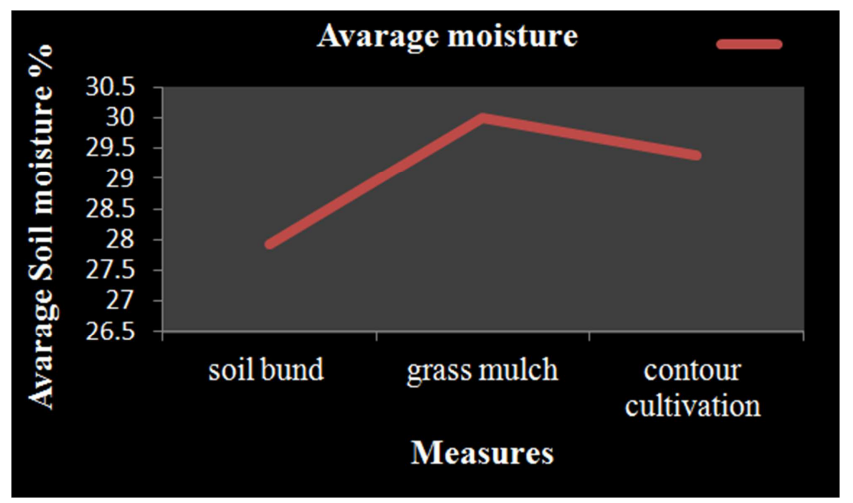

Figure 2. Average moisture (Mc\%) content of the measures over total sampling period. 
Table 9. Average gravimetric soil moisture content over the total sampling period of depth $0-40 \mathrm{~cm}$.

\begin{tabular}{lll}
\hline Measures & Mean \pm SE & CV\% \\
\hline Soil bund $(\mathrm{Sb})$ & $27.94^{\mathrm{b}} \pm 0.20$ & 2.69 \\
Grass mulch $(\mathrm{Gm})$ & $30.00^{\mathrm{a}} \pm 0.01$ & 3.17 \\
Contour cultivation $(\mathrm{Cc})$ & $29.40^{\mathrm{a}} \pm 0.02$ & 2.98 \\
\hline
\end{tabular}

\section{Conclusion and Recommendation}

Soil and water is an important natural resource which provides the required needs for human beings because the whole creations on the earth are depend on soil and water. But its degradation is one of the major environmental problem challenging agricultural production and productivity in many parts of Ethiopia due to unwise use of resources continuously by human being. Even though a number of soil and water conservation methods were introduced and practiced, the area has been experiencing declining soil fertility and soil moisture reduction. This is due to high evaporation rate, continuous cropping of farm land, high population pressure, cultivation of marginal lands and absence of continued use of soil and water conservation measures. In order to solve erosion problem particularly soil moisture content enhancement and improve the production potential of agricultural land, different type of SWC measures and approaches were introduced by governmental and non-governmental institutions. However, the efforts implemented towards the practices of the newly adopted technologies so far seem to have limited impact in increasing the sustained use of SWC measures. Among different physical and biological soil and water conservation measures, soil bund, grass mulch and contour cultivation were selected to analyze the significant impact on soil moisture improvement.

With the reference to the above result and conclusions, the following recommendations are made.

The approaches to expansion of soil and water conservation measures should not be top-down and it should be participatory and depend on the indigenous knowledge of the farmers.

Among tested soil and water conservation measures grass mulch had better soil moisture enhancement and had critical role in reducing evaporation impact, so farmers should use grass as mulch instead of thronging it anywhere.

Sustainable and participatory soil and water conservation measures must be developed to reduce soil moisture loss.

Government should develop a mechanism for initiating the process of land consolidation, which is instead of plowing fragmented pieces of land.

\section{References}

[1] Abebe M. (1998): Nature and management of Ethiopian soil. Alemaya: University of Agriculture, Ethiopia.

[2] Asmare W. (2012): Effect of tied ridging and animal manure application on soil moisture and grain yield of sorghum (sorghum bicolor 1.), notrh wollo, Ethiopia An M. sc. Thesis submitted to Haremaya University.

[3] Amsalu \& De Graaff (2oo4): Determinants of adoption and Continue Use of Stone terraces for soil and water Conservation in an Ethiopian Highland watershade. Journal of Ecological Economics, 2004; 61:294-302.

[4] Baruah and Barthakur (1997): A Text Book of Soil Analysis. Vikas Publishing House PVT LTD. Delhi, India, 12-13.

[5] Baskan et al (2003): A Manual for Semi-arid Areas of Ethiopia: Resource Base, Constraints and Improved Technologies for Sustainable Agricultural Production, mimeo, Addis Ababa, Ethiopia.

[6] Greenland et al (1994): Water productivity in rain-fed agriculture: Challenges and Opportunities for smallholder farmers in droughtprone tropical agroecosystems.

[7] Tekilil w. (2017): Effect of land preparation methods and animal manure application rates on soil moisture conservation and yield of onion (allium cepa) at gode, somali regional state, Ethiopia.

[8] Teklu and Gezahegn (2003): Integration of organic and inorganic fertilizer: effect on vegetable productivity. University of Hohenheim, Soil Science and Land Evaluation, Germany., 1-12.

[9] Walkley, A. and T. A. Black, 1934. An examination of the Degtjareff method for determiningsoil organic matter, and proposed modification of the chromic acid titration method.

[10] Wegayehu. K. 2003: The state of world: A world watch institute report on progress toward a sustainable society Washington DC.wwwworldwatch.org.

[11] World Bank (2003): Risk and Vulnerability Analysis, Addis Ababa, Ethiopia, 2003.

[12] Zamir A. 1994: A text book of surveying (practical geagrashy)

[13] Zerihun J. 2018: Challenges and Opportunities for Smallholder Farmers in Drought-prone Tropical Agro ecosystems., 145-162. In: Kijne, J. W., Barker, R. and Molden, D. (edes).

[14] Zerihun G., 2011: Response of onion (allium cepa var. cepa) to organic and inorganic fertilizers at gode, south-eastern Ethiopia.

[15] Zeuraritu K: 2005: Assessment of socio-economic Factors affecting women participating in environment management in Dar es Salaam City, Tanzania. Dissertation for Award of MSc Degree at Sokoine university of Agriculture, Morogoro, Tanzania, 2004; 84. 